\title{
An analysis of the impacts of health insurance rebate initiatives on community supported agriculture in Southern Wisconsin
}

\author{
Greg Jackson, ${ }^{a}$ Amanda Raster, ${ }^{b}$ and Will Shattuck ${ }^{c}$
}

Submitted 27 February 2011 / Accepted 9 June 2011 / Published online 30 September 2011

Citation: Jackson, G., Raster, A., \& Shattuck, W. (2011). An analysis of the impacts of health insurance rebate initiatives on community supported agriculture in Southern Wisconsin. Journal of Agriculture, Food Systems, and Community Development, 2(1), 287-296. http://dx.doi.org/10.5304/jafscd.2011.021.002

Copyright (C) 2011 by New Leaf Associates, Inc.

\begin{abstract}
Since 2005, four insurance providers in southern Wisconsin have offered rebates to policyholders who subscribe to a local community supported agriculture (CSA) operation. Rebate program par-
\end{abstract}

a Department of Agricultural \& Applied Economics, University of Wisconsin-Madison, 427 Lorch Street, Office 311, Madison, WI 53706 USA; +1-952-200-1912; gsjackson2@wisc.edu

b Department of Horticulture, University of WisconsinMadison; Moore Hall-Plant Sciences, 1575 Linden Drive, Madison, WI 53706 USA; +1-608-262-6965; alraster@wisc.edu

c Department of Agricultural \& Applied Economics, University of Wisconsin-Madison, Mark H. Ingraham Hall, 1155 Observatory Drive, Madison, WI 53706 USA; +1-608- 262-8896; wshattuck@,wisc.edu

Correspondence may be addressed to any of the authors by email.

Note: Senior authorship is shared.

Disclosure: Amanda Raster is a member of the board of directors of the Madison Area Community Supported Agriculture Coalition, but does not receive any remuneration in that role. She does not have any financial interest in the findings or publication of this paper. ticipants rely on the Madison Area Community Supported Agriculture Coalition (MACSAC) — an organization that supports CSA farms and educates consumers about local food systems - to connect the insurance companies with CSA growers and consumers and to manage various aspects of the CSA rebate program, including vetting participating farms. The rebate makes fresh, seasonal, locally and organically grown fruits and vegetables more accessible to consumers by reducing the cost of a CSA share by up to $40 \%$. As a result, CSA members report increased consumption of fruits and vegetables, one of the main goals of the program. With marketing overseen by MACSAC and the insurance companies, the rebate program has led to a reduction in the amount of time growers spend on advertising their operations and recruiting CSA members and has contributed to increased member retention from year to year. Additionally, both the number of MACSAC member farms and the total number of shares offered by these farms have increased substantially since the rebate program's inception. These trends reduce some of the risk growers face and allow them to expand production in order to serve a larger consumer base. These outcomes associated with the 
MACSAC organization and the insurance rebate program indicate the success of the program, the importance of MACSAC as an organizing body, and the potential for implementing the program among national providers and in other locations where community supported agriculture is prevalent.

\section{Keywords}

community supported agriculture, insurance rebates, local food, Wisconsin agriculture

\section{Introduction}

Wisconsin is currently home to more than 202 community supported agriculture (CSA) farms (Local Harvest, n.d.). While these operations vary in size and types of produce offered, all seek to support a localized food system through direct connections between farmers and consumers. Forty-nine of Wisconsin's CSA farms are members of the Madison Area Community Supported Agriculture Coalition (MACSAC). Established in 1992, MACSAC organizes and supports CSA farms and educates consumers about the importance of a locally oriented food system.

In 2005, a health insurance provider in southern Wisconsin launched an innovative program that offers rebates to policyholders who subscribe to a CSA share through a MACSAC farm. Three other insurance companies servicing southern Wisconsin have since started CSA rebate programs of their own. By 2010, the four insurance companies together supplied over 20,400 CSA rebates to their members. Moreover, the number of MACSAC farms increased from 16 farms in 2005 to 42 farms in 2010, while the total number of shares offered annually grew from approximately 2,000 shares in 2005 to 9,000 shares in 2010, for a total of 27,600 shares in that six-year period. This trend suggests that the health insurance rebate program has helped to fuel the growth of community supported agriculture in southern Wisconsin, while at the same time encouraging households to consume more fresh fruits and vegetables and creating a heightened awareness of the local food system.
Owing to data limitations that currently preclude a statistical analysis aimed at isolating the impacts of the insurance rebate program on CSA share supply and demand, this paper will instead seek to draw inferences from observed trends, anecdotal data, and literature on CSA culture in order to explore the favorable consumer response to the CSA rebate program and to recommend future policy objectives. We begin by briefly outlining the concept of CSA and discussing the role of MACSAC in promoting and expanding CSA in southern Wisconsin, especially within the context of making CSA more economically viable for farmers. We then discuss the CSA health insurance rebate within the context of incentivizing healthy behavior and the program's impacts on MACSAC farms. The paper concludes with recommendations to expand the rebate program beyond southern Wisconsin.

\section{Community Supported Agriculture: Motivations and Challenges}

Community supported agriculture arrived in the eastern United States in the early 1980s and has since spread to all regions of the country. In a typical CSA arrangement, shareholders pay at the beginning of the growing season for a supply of weekly "baskets" of fresh, seasonal produce.

Advance payment allows farmers to cover the costs of inputs for that season, provides a stable and predictable income for the growers, and acts as a contract that guarantees - to an extent — weekly deliveries of fresh produce throughout the growing season. Emerging interest in local, organic, and sustainable food production in the United States has fueled continued growth in the popularity of CSA over the past decade, such that there are now CSA farms and "shareholders" in all 50 states (Local Harvest, n.d.). In 2010, there were over 3,800 CSA farms in operation in the United States and tens of thousands of subscribing households (Martinez, 2010; Local Harvest, n.d.). While relatively little research has been done to examine the factors contributing to the growth of CSA and its associated impacts, the increase in market share of organic vegetables - up 5.1\% to US $\$ 24$ billion in 2009, according to USDA estimates - and increased interest in local food and "civic" agri- 
culture signal the potential for further growth in the popularity of CSA (Martinez, 2010).

Farmers start CSA operations for numerous reasons, primarily to foster a stronger sense of community between grower and consumer and also to produce food using more sustainable methods (Woods, Ernst, Ernst, \& Wright, 2009; Cooley \& Lass, 1996). Although these are important motivators in the early stages and long-term operation of the farm, CSA growers face abundant challenges in maintaining a successful CSA program and farm operation in general. The results of a 10-year study conducted through 2006 illustrate some of the obstacles that CSA farmers face (Ostrom, 2007). Ostrom reported that of the 24 farms involved at the beginning of the study period, only 10 were still in operation by the end. Economic, health, and quality of life issues were all factors contributing to the failure of the CSA operations. Tegtmeier and Duffy (2005) further support the notion of economic challenges within CSA operations, finding that of the 55 Upper Midwestern CSA farmers surveyed in the spring of 2002 , less than half felt that the share prices they charged to their members represented a fair return on their labor. The authors relate that the perception of obtaining a fair wage was associated with increasing revenues per acre as well as capital investments, the latter conveying the sense that smaller-scale operations could be at a disadvantage compared with their larger counterparts. Owing largely to the extent of operating costs coupled with a low share price, over half of CSA farmers surveyed in 2000 relied on off-farm income to make ends meet, a trend that, according to the 2007 Census of Agriculture, continues today (Sabih \& Baker, 2000; USDA, 2009). Additionally, Woods et al. (2009) remark that $87 \%$ of the 205 respondents to a 2009 survey of CSAs in the American South and Midwest cited the use of marketing channels outside the CSA operation, such as farmers' markets, in an effort to diversify income. Sabih and Baker (2000), Oberholtzer (2004), and Brown and Miller (2008) report in their respective studies that CSA operators were barely able to cover operating costs and that many did not factor in a salary for themselves or family members as part of these costs. Moreover, Ostrom (2007) noted that most CSA farms in the 2006 study referenced above could "only charge what the market would bear" (p. 118), which did not allow for prices that covered both operating costs and an adequate salary for operators and their families.

Another economic obstacle that CSA farmers face is member retention and recruitment (Tegtmeier \& Duffy, 2005). A study conducted by the Small Farm Success Project found an average annual retention rate of $53 \%$ among CSA farms (Oberholtzer, 2004). Despite the fact that surveys conducted by farms and researchers have helped CSA farmers better understand the preferences of their members, CSA farmers still invest considerable time recruiting and advertising their operations (Perez, Allen, \& Brown, 2003). Common CSA marketing channels include word-of-mouth, the Internet, various forms of social media, and more traditional methods such as print advertising. Additionally, many CSA farms also operate their own websites to inform prospective shareholders about their core mission, share offerings, and farm activities and events. The necessity of both retaining and recruiting members presents yet another challenge to CSA farmers in that it requires them to divert time otherwise invested in production and farm maintenance to marketing, with no guarantee that the membership numbers for a given season will meet the numbers necessary to keep the CSA operation afloat.

From the consumer side, Kolodinsky and Pelch (1997) model consumer propensity to participate in community supported agriculture in Vermont, finding that not only are potential CSA consumers price sensitive, but also that factors such as the presence of children under the age of 12 in the household are associated with a decrease of about $20 \%$ in the probability of joining a CSA. It is therefore important to consider that, holding all else equal, the influences of price and income alone on produce consumption may not carry a direct correlate with CSA membership uptake.

The challenges that thus confront CSAs on account of lower share prices and/or perceptions 
of shortfalls in returns on efforts are often reasoned to be offset by certain "intangible benefits" (Tegtmeier \& Duffy, 2005) that arise from engaging in CSA operation, in line with the above discussion on the motivations behind starting up a CSA. Drawing inferences from this pool of literature, subsidizing the cost of a CSA share may be one way to effectively reduce the price to the consumer while allowing growers to receive an adequate salary and thus increasing the economic feasibility of the operation.

\section{Madison Area CSA Coalition}

Established in 1992, the Madison Area Community Supported Agriculture Coalition (MACSAC) supports and connects CSA growers and eaters through a range of activities. These include a farmer mentorship program, grower gatherings, community educational workshops, an annual open house where the public can meet MACSAC farmers and sign up for CSA memberships, a bimonthly newsletter, and distribution of MACSAC's CSAfocused cookbook. The organization also works to increase access to fresh organic produce through the Partner Shares Program, which provides financial assistance to help low-income families purchase CSA shares from MACSAC's member farms. MACSAC consists of a board of directors and three employees who oversee the organization's administration and programming. This structure allows for input and active participation in the organization's activities from both the farmer and consumer communities.

Each MACSAC farm undergoes an application and review process before it is accepted as a member of the coalition. Prospective farms are assessed according to criteria that are designed to ensure that each farm has the necessary production skills, marketing experience, land, equipment and facilities, communication infrastructure, and knowledge about community supported agriculture in order to manage a successful operation, produce high quality fruits and vegetables, and cultivate a positive overall experience for CSA members. Additionally, MACSAC requires all member farms to be certified organic by a federally approved certifying agency. Farms with annual sales of less than US $\$ 5,000$ are exempt from certification but are required to meet all of the standards of the National Organic Program. Endorsed farms are eligible to receive MACSAC benefits, including placement on the annual MACSAC Farm List, access to grower mentorship and resources, participation in the annual open house and the Health Plan Partners Program (i.e., CSA rebate), and other activities (Madison Area Community Supported Agriculture Coalition [MACSAC], n.d.).

Over 60 farms have belonged to MACSAC at one time or another, serving memberships as small as four and as large as over 1,000 and providing tens of thousands of shareholders with fresh, locally grown, organic produce (Hendrickson, 2011). Share prices among MACSAC farms have increased from an average of US\$375 for a "standard" share (which typically feeds a family of four) in 1993 to an average of US $\$ 550$ today (MACSAC, 2010a). "Small" or "half" shares are becoming more common and are typically priced around US $\$ 375$. Throughout these changes in farm membership, share availability, and share price, MACSAC has remained committed to its mission of fostering cooperation and educational opportunities among its farmer members while promoting and advancing a community-based food system.

\section{The CSA Insurance Rebate Program}

In 2005, MACSAC began to partner with major health insurance providers in southern Wisconsin to promote preventative wellness, healthy eating, and local food through CSA membership rebates. Launched in 2005, the Health Plan Partners Program was the brainchild of one insurance provider that was looking to differentiate itself from competing health insurance companies by shifting away from traditional marketing techniques toward more community engagement initiatives. In search of a

\footnotetext{
${ }^{1}$ MACSAC has kept records of varying detail on participation among its member farms over the past 19 years. The authors were granted access to this data in order to quantify the growth in CSA over this period. Household-level data is currently unavailable; however, a pending survey of MACSAC farmers and their CSA members will facilitate greater statistical analysis of the rebate program in the near future.
} 
structure through which to encourage its policyholders to eat more fruits and vegetables, the insurance provider partnered with MACSAC on account of its standards that require member farms to produce quality, fresh produce using sustainable farming practices.

During the pilot year in 2005, two MACSAC farms and 96 health insurance policyholders participated in the rebate program (L. Brown, personal communication, November 1, 2010). Reaction was so positive that the total number of MACSAC member farms increased from 16 to 26 the following year, in part to meet the heightened demand for CSA memberships among policyholders. This increase represented an unprecedented rate of growth for MACSAC at the time. Moreover, farms filled their memberships more quickly that year, a trend that has continued each year since.

Following on this success, one additional health insurance provider in the Madison area began to offer the CSA rebate in 2007, and two more providers added the rebate in 2008. Each of the carri- ers has partnered with MACSAC, through the Health Plan Partners Program, for administrative and marketing purposes. Under this arrangement, insurance providers are responsible for creating advertising materials to promote the CSA rebate program to policyholders and for supplying MACSAC with informational newsletters about their wellness programs, which are distributed to MACSAC farms and their shareholders. The insurance providers also direct policyholders to the MACSAC website, where they can learn about community supported agriculture and each of MACSAC's member farms. In turn, MACSAC promotes the rebate program and participating insurance providers through its outreach and education efforts. In 2006 alone, the program generated over 16 million total gross media impressions nationwide (Physicians Plus Insurance Corporation, 2007). Newspapers and sustainable agriculture networks across the U.S. spread the program's success story, and Madison-area news sources provided especially favorable coverage.

Local news outlets touted the rebate program as a

"visionary decision" that raised public awareness of community supported agriculture and provided insurance policyholders a great way to take responsibility for their health (Bergin 2010, p. 17).

This unique advertising and marketing arrangement has contributed to a substantial increase in the number of health insurance policyholders claiming CSA rebates, from 
the original 96 rebates claimed in 2006 to over 6,000 claimed in 2010 (table 1). To obtain the rebate, policyholders must provide their respective insurance companies with a copy of their farm sign-up form and proof of payment (i.e., receipt from the farm). Rebate values range from US $\$ 50$ to US $\$ 100$ for an individual and up to US $\$ 200$ for a family. This represents a price reduction of roughly $40 \%$ when compared to the average MACSAC farm price of US $\$ 550$ for a 20 -week, standard share subscription.

That three additional insurance providers picked up the CSA rebate program so quickly after it was initiated suggests that doing so was a competitive response to retain members who may have otherwise switched to the initiating provider in order to take advantage of the incentive to purchase locally produced fruits and vegetables. In fact, the practice of incentivizing improved consumer behavior through various health insurance mechanisms is not a novel idea. Finkelstein, Fiebelkorn, and Wang (2003) observed that costs associated with obesityrelated issues arise in the form not only of higher insurance premiums for company health plans, but also in productivity losses, such as work absences by employees with obesity problems. As such, Finkelstein and Kosa (2003) found evidence in favor of charging higher insurance premiums for obese employees who refuse to participate in weight-management programs, or offering discounts and reductions in copayments for healthy behavior. In support of the latter, Arterburn et al.
(2008) found that $41 \%$ of health insurance subscribers surveyed in the state of Washington agreed that financially based incentive programs would encourage weight loss. While there is a strong potential for positive health benefits in the long run among policyholders who participate in health incentive programs, in the case of southern Wisconsin, the Health Plan Partners insurance providers could likely be incentivized by the promotional benefits of offering the CSA rebate, namely that it ties them to the local food movement and the increasing propensity toward healthy eating and purchasing organic foods, thus giving them additional exposure in the community through which new policyholders may be obtained.

\section{Impact of the CSA Rebate Program on MACSAC Farms}

Since the inception of the CSA rebate program, the demand for CSA shares in southern Wisconsin has increased substantially. In 2005, the pilot year of the rebate program, MACSAC farms offered approximately 2,000 shares in total, compared to 9,000 in 2010. This represents an increase of $450 \%$ over five years (see figure 1). Conversely, the previous five years (2000-2005) saw an increase of $137 \%$ in the number of shares offered by

MACSAC farms, suggesting that the growth in available shares is closely associated with the success of the CSA rebate program. Moreover, since 2005, nearly 30 new CSA operations have joined MACSAC in order to take advantage of the demand for shares associated with the rebate, in

Table 1. Number of CSA Rebates Claimed, 2005-2010

\begin{tabular}{rrrrrr}
\hline Year & Insurance Co. 1 & Insurance Co. 2 & Insurance Co. 3 & Insurance Co. 4 & Total \\
\hline 2005 & 96 & - & - & - & 96 \\
\hline 2006 & 972 & - & - & 261 & 972 \\
\hline 2007 & 1,282 & - & 965 & 689 & 4,543 \\
\hline 2008 & 1,486 & 1,564 & 1,290 & 918 & 6,704 \\
\hline 2009 & 1,637 & 2,645 & 1,475 & 1,049 & 6,274 \\
\hline 2010 & 1,746 & 2,334 & 3,730 & 2,917 & 6,624 \\
\hline Total & 7,219 & 6,543 & 20,429 \\
\hline
\end{tabular}

Sources: Madison Area Community Supported Agriculture Coalition, 2010; participating insurance providers. 
addition to the other benefits derived from being a member of the coalition.

While individuals involved in developing the Health Plan Partners Program claim that there is a "direct correlation between the rebate and the growth in CSA memberships," MACSAC acknowledges the difficulty in attributing a causal relationship, as no published econometric work has yet been undertaken to measure the direct effect of the program on membership uptake (K. Auberbach, personal communication, November 4, 2010; K. Mulvey, personal communication, November 18, 2010). Because an individual's decision to become a CSA shareholder is influenced by a host of motivations, factors such as the heightened profile of local foods may be an equally important contributing influence, thus confounding the impacts of the rebate program alone. Additionally, it is possible that shareholders requesting farm receipts for their CSA share may be using them for purposes other than claiming the insurance rebate. Thus, relying on farm data alone may lead to inaccurate interpretations of the impact of the rebate program in terms of CSA memberships.

However, responses from 45 Partner Shares Program participants (see description of program above) in a MACSAC survey in 2010 convey some element of price sensitivity with respect to CSA memberships, suggesting that measures to draw down share prices could render favorable results in relation to increased memberships. Specifically, about two-thirds of the survey respondents reported that financial assistance was necessary in enabling their purchase of a CSA share in the 2010 season, and close to $90 \%$ intended to participate in the program again in 2011 (MACSAC, 2010b). While a promising statistic, it is necessary to account for the fact that Partner Shares participants qualify for assistance based on meeting certain household income characteristics. Therefore, financial assistance provided through such mechanisms as Partner Shares and the rebate program help to increase the accessibility of CSA across multiple income demographic groups that may otherwise not be able to afford the expense.
Additionally, the CSA rebate program has allowed farmers to spend less time advertising and recruiting new members and more time diversifying their operations and growing high quality produce. Rather than relying solely on their own marketing efforts and word of mouth among existing shareholders, MACSAC farms benefit from the increased exposure from promotional, educational, and outreach activities related to the rebate program. Furthermore, survey responses from MACSAC member farms demonstrate that the rebate program has helped to improve retention of existing members, as the rebate helps to buffer increases in CSA share cost from year to year.

Lastly, the economic value of the Health Plan Partners insurance rebate with regard to CSA memberships is substantial. Over the six-year period of the program, a back-of-the-envelope calculation using an extrapolation of the average percentages of individual versus family rebates claimed for two of the insurance companies yields the rough estimate of US $\$ 3,049,000$ in rebates issued to policyholders. Additionally, using MACSAC data to multiply the average share price for both standard and half shares by the number of standard and half shares purchased, respectively, during the years 2005-2010, we estimate that the total value of CSA shares purchased in this period was US $\$ 14.2$ million, placing the value of the rebates at roughly $21 \%$ of the total value of shares purchased. Not only do the CSA rebates open up opportunities through a lower effective share price, but the proportion of the value of rebates claimed relative to the total value of CSA shares purchased $(21 \%)$ could essentially be viewed as the insurance companies' contribution to policyholder health and wellness and promotion of local agriculture. Moreover, the lower effective share price keeps consumers at a higher level of disposable income, which in turn brings its own set of economic benefits through additional consumer expenditures in the community. The figures listed above thus demonstrate a positive economic impact on consumers. Perhaps more importantly for the CSA operations involved, the effectively lower price for consumers allows farmers to continue charging a share price that more closely mirrors the true value of the 
share including, as Brown and Miller (2008) among others point out, an adequate salary for growers and their families. Consequently, incentives such as the health insurance rebate help to create a more economically viable operation for a subset of the agricultural community that struggles with a relatively high rate of farmer attrition.

\section{Conclusion}

Given this analysis, we conclude that the CSA insurance rebate program has been positively received, in particular by the consumer population. As previously noted, the total number of CSA shares offered by MACSAC farms has increased due to growth in both the number of member farms and the number of shares offered per farm. While some of this growth may by attributed to expanding interest in local food and increasing concern over the methods of modern agricultural production, a substantial portion can likely be attributed to the membership demand associated with the Health Plan Partners CSA rebate program. As previously noted, although household level data, such as demographic and socioeconomic characteristics, associated with the rebate program is not available for privacy reasons, anecdotal evidence indicates a strong response to the price incentive rendered from the program. Specifically, claiming the CSA rebate can reduce the price of a standard share by up to $40 \%$, bringing the cost close to the average household expenditure on fruits and vegetables for the same length of time, according to the U.S. Census Bureau (2000).

At the same time, it should be noted that there is concern among MACSAC growers that the rebate program has attracted a "new" type of CSA member, namely that those joining a CSA farm in order to obtain the rebate may lack awareness about the traditional relationship between CSA farmer and member, specifically with respect to the philosophy of shared risk. For example, the new CSA member may expect farms to provide specific types of produce in specific volumes throughout the growing season, irrespective of environmental factors that may inhibit production. To this end, MACSAC growers agree that the concept of shared risk, and education about CSA in general, should be more clearly communicated to prospective members who may be looking for value in a CSA share versus a direct relationship with a farmer. Thus, as the decline in the effective price of CSA shares welcomes in a new type of CSA shareholder, it also opens the door for improved educational opportunities about risk-sharing, the importance of local agriculture, and community-building and environmental stewardship, all of which are fundamental tenets of the CSA philosophy.

Furthermore, based on responses from parties involved, it appears that the Madison Area CSA Coalition is a key element in the rebate program's continued existence and function. In light of the rigorous application and review process that prospective member farms must go through in order to join the coalition, MACSAC acts as a clearinghouse for partnering insurance companies with regard to the quality of farms involved in the program and their ability to provide CSA members with a positive experience. This partnership reduces the need for high-level marketing of the program on the insurance companies' end and streamlines the communication chain between insurance companies and participating farms. Yet, while there is significant interest nationally in bringing a similar rebate program to other states or regions, there have been no successful replications to date (K. Mulvey, personal communication, November 18, 2010). For example, attempts made in 2010 to encourage a health insurance provider in western Wisconsin to pilot the rebate program independently of MACSAC (although in collaboration with a MACSAC member farm) have proved unsuccessful thus far. As a result, plans are now in the works to incorporate the insurance provider into the Health Plan Partners Program, in affiliation with MACSAC. Therefore, we hypothesize that replication of the CSA rebate program across the country is largely contingent on having an organization like MACSAC to serve as an intermediary between health insurance providers and CSA farmers and consumers.

There is much room for further research into the dynamic between insurance rebates and expansion of the CSA model as a means to enhance quality of 
life for both consumers and producers. While the 2007 Census of Agriculture (USDA, 2009) included data on community supported agriculture for the first time, better data collection at the local and national levels will allow for improved analysis of the growth and economic impacts of CSA, as well as programs like the health insurance rebate. Despite the current lack of data to conduct an empirically oriented investigation into the exact impacts of the rebate program on CSA membership in southern Wisconsin, the success of this initiative appears to be demonstrated through the experiences of the four health insurance companies discussed throughout this paper, in addition to the increase in both MACSAC farms and total number of CSA shares offered by MACSAC farms since the program's inception. Therefore, transplanting the Healthy Plan Partners model to other areas within Wisconsin, as well as to different regions of the United States, is recommended as a future policy objective, provided that an organization such as MACSAC is in place to facilitate the connections between health insurance providers, farmers, and consumers interested in community supported agriculture.

\section{Acknowledgements}

The authors are indebted to University of Wisconsin-Madison Professor Brent Hueth for his guidance and editing, and to Kathryne Auerback, Laura Brown and the staff at MACSAC for providing access to data and information on CSA and the insurance rebate program.

\section{References}

Arterburn, D., Westbrook, E. O, Wiese, C. J., Ludman, E. J., Grossman, D. C., Fishman, P. A., Finkelstein, E. A., Jeffery, R. W., \& Drewnowski, A. (2008). Insurance coverage and incentives for weight loss among adults with metabolic syndrome. Obesity, 16, 70-76. http://dx.doi.org/10.1038/oby.2007.18

Bergin, M. (2010, February). Special Delivery. Madison Magazine.

Brown, C., \& Miller, S. (2008). The impacts of local markets: A review of research on farmers markets and community supported agriculture. American Journal of Agricultural Economics, 90, 1296-1302.
Cooley, J. P., \& Lass, D. A. (1996). What's your share worth? Some comparisons of CSA share cost versus retail produce value. Stillwater, New York: CSA Farm Network Publications.

Finkelstein, E. A., Fiebelkorn, I. C., \& Wang, G. (2003). National medical spending attributable to overweight and obesity: How much, and who's paying? Health Affairs, W3, 219-226.

Finkelstein, E. A., \& Kosa, K. M. (2003). Use of incentives to motivate healthy behaviors among employees. Gender Issues, 21(3), 50-59. http://dx.doi.org/10.1007/s12147-003-0005-0

Hendrickson, J. (2011). History of MACSAC: The Madison Area Community Supported Agriculture Coalition, a retrospective. Retrieved from http://www.csacoalition.org/about/history/

Kolodinsky, J. M., \& Pelch, L. L. (1997). Factors influencing the decision to join a community supported agriculture (CSA) farm. Journal of Sustainable Agriculture, 10(2/3), 129-141. http://dx.doi.org/10.1300/J064v10n02 11

Local Harvest. (n.d.). Community Supported Agriculture. Retrieved from http://www.localharvest.org/csa/

Madison Area Community Supported Agriculture Coalition (MACSAC). (n.d.). Become a coalition farm. Retrieved from http://www.csacoalition.org/ our-work/farm-programs/\#newfarm/

Madison Area Community Supported Agriculture Coalition (MACSAC). (2010a). MACSAC farms and shares through 2010. [Excel spreadsheet].

Madison Area Community Supported Agriculture Coalition (MACSAC). (2010b). Partner Shares survey 2010. [Excel spreadsheet].

Martinez, S. W. (2010). Varied interests drive growing popularity of local foods. Amber Waves - The Economics of Food, Farming, Natural Resources, and Rural America (published by the USDA Economic Research Service), 8(4), 10-17.

Oberholtzer, L. (2004). Community supported agriculture in the Mid-Atlantic region: Results of a shareholder survey and farmer interviews. Retrieved from http://www.winrock.org/wallace/wallacecenter/ documents/wc-CSAReport.pdf

Ostrom, M. R. (2007). Community supported agriculture as an agent of change: Is it working? In C. C. Hinrichs \& T. A. Lyson (Eds.), Remaking the North American Food System: Strategies for Sustainability (pp. 99-120). Lincoln, Nebraska: University of Nebraska Press. 
Perez, J., Allen, P., \& Brown, M. (2003). Community supported agriculture on the Central Coast: The CSA member experience. University of California at Santa Cruz: Center for Agroecology and Sustainable Food Systems. Retrieved from http://escholarship.org/ uc/item/5wh3z9jg

Physicians Plus Insurance Corporation. (2007). Eat Healthy Rebate Program Description. Madison, Wisconsin: Self.

Sabih, S. F., \& Baker, L. B. B. (2000). Alternative financing in agriculture: A case for the CSA method. Acta Horticulturae (ISHS), 524, 141-148. Retrieved from http://www.actahort.org/books/ 524/524 16.htm

Tegtmeier, E., \& Duffy, M. (2005). Community supported agriculture (CSA) in the Midwest United States: $A$ regional characterization. Leopold Center for Sustainable Agriculture, Iowa State University.
United States Census Bureau. (2000). Income, expenditures, poverty \& wealth. Retrieved from http://www.census.gov/compendia/statab/cats/ income expenditures poverty wealth.html

United States Department of Agriculture (USDA). (2009). 2007 Census of Agriculture: United States summary and state data. (Volume 1 Geographic Area Series Part 51, Publication No. AC-07-A-51). Washington, DC: National Agricultural Statistics Service.

Woods, T., Ernst, M., Ernst, S., \& Wright, N. (2009, July). 2009 survey of community supported agriculture producers. Agricultural Economics Extension Series 2009-11, University of Kentucky Cooperative Extension Service, pp. 1-24. 